\title{
Temperature variability at Siple Dome, West Antarctica, derived from EGMWF re-analyses, SSM/I and SMMR brightness temperatures and AWS records
}

\author{
Sarah B. Das, ${ }^{1}$ Righard B. Alley, ${ }^{1}$ David B. Reusch, ${ }^{1}$ Ghristopher A. Shuman ${ }^{2}$ \\ ${ }^{1}$ Department of Geosciences and Environment Institute, The Pennsylvania State University, University Park, PA 16802-7501, U.S.A. \\ ${ }^{2}$ Oceans and Ice Branch, NASA Goddard Space Flight Center, Code 971, Greenbelt, MD 20771, U.S.A.
}

\begin{abstract}
We produced four independent temperature time series derived from different sensors for the Siple Dome region of West Antarctica to investigate seasonal to interannual temperature variability over the last 20 years. We use data from automatic weather station air-temperature records (1997-99), European Centre for Medium-range Weather Forecasts surface temperature from the 15 year re-analyses (ERA-15, 1979-93), and emissivity-corrected brightness temperatures from the Special Sensor Microwave/ Imager (1987-99) and the Scanning Multichannel Microwave Radiometer (1978-87). Each technique has limitations and errors, but all respond to temperature, and all agree in the large patterns of temperature variability over time. Our results show that there is high seasonal to interannual variability in both mean temperature and variance in the Siple Dome region during the study period. In particular, fluctuations in seasonal to interannual temperature variance occur on an approximately 5 year cycle and correlate with variations in the Southern Oscillation Index.
\end{abstract}

\section{INTRODUGTION}

Paleoclimate reconstructions from ice cores have improved our understanding of how the polar and global climate systems work, how climate has changed in the past and how it might change in the future (Alley, 2000). Interpreting past environmental change over the polar regions, including past temperature changes, from snow, firn and ice cores requires a greater understanding of the processes affecting current ice-sheet surface conditions. Siple Dome, West Antarctica $\left(81.65^{\circ} \mathrm{S}, 148.81^{\circ} \mathrm{W}\right.$; Fig. 1$)$, is the location of a recent deep ice-coring project as well as numerous other glaciological and climate studies (Bindschadler and others, 1998). The only in situ surface temperature information presently available for Siple Dome is from meteorological data collected by an automatic weather station (AWS) in operation since early 1997. This record is too short to accurately characterize the present-day temperature cycle in this region.

The purpose of this study is to extend the length of the temperature record at Siple Dome in order to understand the regional seasonal to interannual temperature variability and controls. This will improve our ability to interpret the paleotemperature record from stable isotopes, borehole thermometry, melt-layer thermometry and physical stratigraphy of the Siple Dome ice cores. These paleoclimate proxies preserved by the ice sheet are sensitive not only to mean annual temperature, but to seasonal and annual temperature variability as well. Furthermore, we are interested in understanding controls on seasonal- to decadal-scale climate processes and variability in the Siple Dome/"Ross Embayment" sector of West Antarctica and how these have changed through time. For this study we have combined the 3 years of local AWS data with proxy surface temperature data from global climate model (GCM)-scale meteorological re-analyses and passivemicrowave brightness-temperature records. While we recognize that in situ temperature data are clearly preferable for purposes of climatological analyses, we can only extend

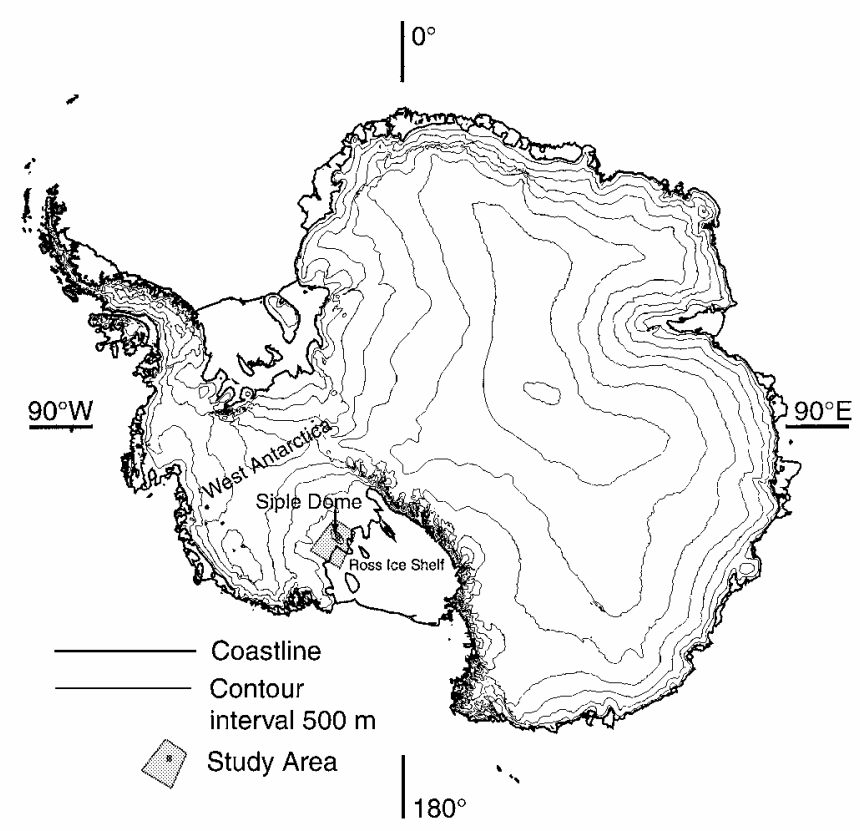

Fig. 1. Location map of Antarctic showing the study area surrounding Siple Dome. The gray shaded box represents the geographic boundaries of the ERA-15 model output used in calculating the surface temperature $T_{\mathrm{S}}$. The dot inside the box represents the location of the AWS unit near the summit of Siple Dome. 
the length of the temperature record for this region by turning to other sources of proxy temperature information (while bearing in mind the inherent inaccuracies introduced by using calculated or modeled surface temperatures). Here we present our techniques and results utilizing these different sources of temperature information to extend the length of the seasonally resolved surface temperature record in the vicinity of Siple Dome and to investigate the regional temperature variability from 1979 to 1999. Each of the four techniques used has limitations and responds to slightly different climatic factors, but all respond to temperature change, and all produce agreement on patterns of temperature variability during times of overlap.

\section{DATA ANALYSIS}

\section{AWS air temperature, $T_{\mathrm{A}}$}

Near-surface observations are available from air-temperature records collected by the University of Wisconsin's AWS network in West Antarctica. An AWS unit was deployed at the Siple Dome site (Fig. 1) on 21 January 1997, located at $81.66^{\circ} \mathrm{S}, 148.77^{\circ} \mathrm{W}$ (Stearns and others, 1999). The unit continues to be operational through the present time. Air temperature is measured initially at a height of $3 \mathrm{~m}$ above the surface; snow accumulation around the tower over time reduces the height of the sensor above the snow surface. During the 3 year period of this study, accumulation rates around the AWS tower averaged $30 \mathrm{~cm}$ of snow per year (field measurements by S. Das). As a result, the height above the surface of the air-temperature sensor decreased by approximately $1 \mathrm{~m}$. This quasi-continuous accumulation gradually and progressively lowers the height of the sensor, which can have a significant effect on the trend of the air-temperature record over the entire 3 year period or longer, but it should not impact our present analysis of seasonal to annual temperature variability. We are using the first 3 years of data from this AWS from January 1997 through 31 December 1999. The data are available as quality-controlled averages in a 3 hourly format from the University of Wisconsin file transfer protocol server (ftp://ice.ssec.wisc.edu). Further detailed information about the AWS units can be found in Stearns and Weidner (1993). For the purposes of this study we computed daily-average AWS temperatures from the 3 hour data. We refer to AWS-derived air temperature as $T_{\mathrm{A}}$.

\section{ECMWF re-analysis (ERA-15) surface temperature, $T_{\mathrm{S}}$}

We are using ERA-15 surface temperature data as another source of temperature information for the Siple Dome region. Analysis and model predictions from weather-forecasting centers are used as physically based proxies for climate information in regions with few meteorological observations, such as over much of Antarctica (Genthon and Braun, 1995). The European Centre for Medium-range Weather Forecasts (ECMWF) provides global weather predictions based on atmospheric general circulation model simulations. These model-based predictions are then updated using observations reported by weather stations, satellites and other operational means of weather forecasting. The ECMWF re-analysis (ERA) project produced a 15 year dataset using a fixed analysis and forecasting model for the period 1979-93 (ERA-15) to improve the temporal accuracy and consistency of these operational analyses. For further description of the
ECMWF forecast model, the operational analyses and the reanalyses see Gibson and others (1999) and references therein.

ERA-15 provides global records of temperature (as well as other meteorological variables such as atmospheric moisture, pressure, and wind speed and direction) at 6 hour intervals, on a $2.5^{\circ}$ by $2.5^{\circ}$ grid. While clearly no GCM-scale model can provide completely accurate climate information, especially over a region as poorly understood as Antarctica, these ECMWF data are still a valuable source of regional climate information for the past couple of decades, and have been used in this way in a number of recent studies over Antarctica (Genthon and Braun, 1995; Genthon and Krinner, 1998; Bromwich and others, 2000). (In the future, ECMWF plans to produce a 40 year re-analysis dataset (ERA-40) which will allow us to further investigate the accuracy of these data by providing overlapping data between ERA-40 surface temperatures and longer records of AWS air-temperature data.) Due to the gridcell nature of the ECMWF data $\left(2.5^{\circ}\right.$ latitude $\times 2.5^{\circ}$ longitude $)$ a single cell represents an extremely long and narrow swath at the high latitude of our study site (approximately $280 \mathrm{~km} \times 40 \mathrm{~km}$ ). For our purposes we selected five adjacent gridcells that together form a relatively square area around Siple Dome $(280 \mathrm{~km}$ $\times 200 \mathrm{~km}$; see Fig. 1), and extracted the surface temperature information for these cells for the ERA-15 analysis period 1979-93. We then averaged together the temperature information from each cell to produce a single temperature value for each 6 hour time interval. We chose to average data from the five adjacent cells (shown geographically together in the grey box outline in Figure 1) to best represent the regional climatology around Siple Dome. We refer to these ERA-15 spatially averaged surface temperature data as $T_{\mathrm{S}}$.

\section{SSM/I and SMMR brightness temperature, $T_{\mathrm{B}}$}

Given the limited spatial and temporal extent of in situ measurements (including surface temperature) over the polar regions, scientists often have to turn to satellite remote sensing to study snow and ice properties (for recent reviews see Bindschadler and others, 1998; Konig and others, 2001; for recent surface temperature studies see, e.g., Steffen and others, 1993; Shuman and others, 1995a; Comiso, 2000). One way to do this is to use data from passive-microwave sensors which measure the brightness temperature $\left(T_{\mathrm{B}}\right)$ of radiation emitted from the surface, which is strongly controlled by the surface (and near-surface) temperature. Over the dry-snow facies (Benson, 1962) of Antarctica and Greenland, $T_{\mathrm{B}}$ is primarily controlled by the physical temperature of the firn, with smaller effects from the emission characteristics of the firn, which depend on radiative scattering from the ice grains (over the skin depth of less than one to a few meters), controlled by the grain-size, density, layering and temperature of the firn (Zwally, 1977; Comiso and others, 1982; Foster and others, 1984; Hall, 1987; Rott and others, 1993; Steffen and others, 1993).

We are using brightness-temperature satellite data from the Scanning Multichannel Microwave Radiometer (SMMR) (1979-87) and Special Sensor Microwave/Imager (SSM/I) (1987-99) sensors. Both the SMMR and SSM/I instruments measure brightness temperatures at multiple frequencies and polarizations. The data are provided by the U.S. National Snow and Ice Data Center (NSIDC) and are gridded in polar stereographic projection into $25 \mathrm{~km}$ $\times 25 \mathrm{~km}$ gridcells. The NSIDC daily averages are calculated 
Calculated emissivities
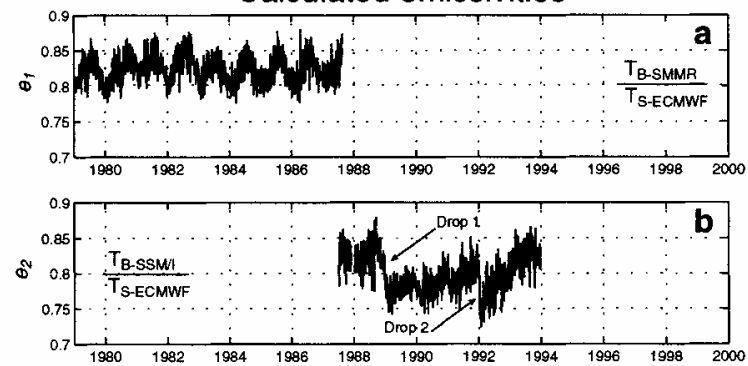

Fig. 2. Temporal trends in surface microwave emissivity values e calculated from comparisons between (a) overlapping $S M M R$ and ECMWF temperature records and (b) SSM/ $I$ and ECMWF temperature records. The mean value of $e$ from each overlapping region was then used to compute corrected temperatures $\left(T_{\mathrm{C}}\right)$ from the microwave brightness temperatures $\left(T_{\mathrm{B}}\right)$. Drops 1 and 2 in (b) are discussed further in the text.

by summing the brightness temperatures which fall into one gridcell for a 24 hour period and then dividing by the number of observations (NSIDC, 1992). For our time-series investigations we extracted daily $(\mathrm{SSM} / \mathrm{I})$ and every other day (SMMR) binned and averaged data points for the gridcell covering the Siple Dome AWS. We combined the $T_{\mathrm{B}}$ records from the three $\mathrm{SSM} / \mathrm{I}$ sensors (F08, F11 and F13) into a single time series (e.g. Abdalati and Steffen, 1995). Since there are some discrepancies between the SSM/I and SMMR data (Jezek and others, 1991) we did not combine the SSM/I data with the SMMR data into a single time series.

As our focus in this study is on the surface temperature variability, we then constructed a surface temperature record from the passive-microwave brightess-temperature data. To do this we used only the $37.0 \mathrm{GHz}$ frequency, vertically polarized (37-V) SSM/I and SMMR data. This channel shows the best statistical correlation with air temperature (Van der Veen and Jezek, 1993; Shuman and others, 1995a) because the $37 \mathrm{GHz}$ channels have a shallower skin depth (approximately the top meter of firn) than the 22 or $19 \mathrm{GHz}$ channels, and will therefore respond faster to surface temperature changes (Steffen and others, 1993). As this skin depth is similar to the penetration depth of the diurnal temperature cycle (Alley and others, 1997), the daily $T_{\mathrm{B}}$ values track the air temperature with little lag (Shuman and others, 1995a). Also the vertical polarization was chosen as it is less sensitive than the horizontal polarization to changes in near-surface snow characteristics, which would have a stronger effect on emissivity values (Shuman and others, 1993). Due to the cold, dry atmosphere above Antarctica, atmospheric effects on $37 \mathrm{GHz}$ brightness temperature are assumed to be negligible (Maslanik and others, 1989).

\section{Calculated brightness temperatures, $T_{\mathrm{C}}$}

The microwave brightness temperature $\left(T_{\mathrm{B}}\right)$ of the nearsurface snow is linearly related to physical snow temperature $(T)$ by the Rayleigh-Jeans approximation (Foster and others, 1984; Hall and Martinec, 1985):

$$
T_{\mathrm{B}}=e T \text {, }
$$

where $e$ is the emissivity of the snow and is $<1$.

If brightness-temperature $\left(T_{\mathrm{B}}\right)$ values are to be used as a proxy for physical surface temperatures $\left(T_{\mathrm{S}}\right)$, snow emissivity
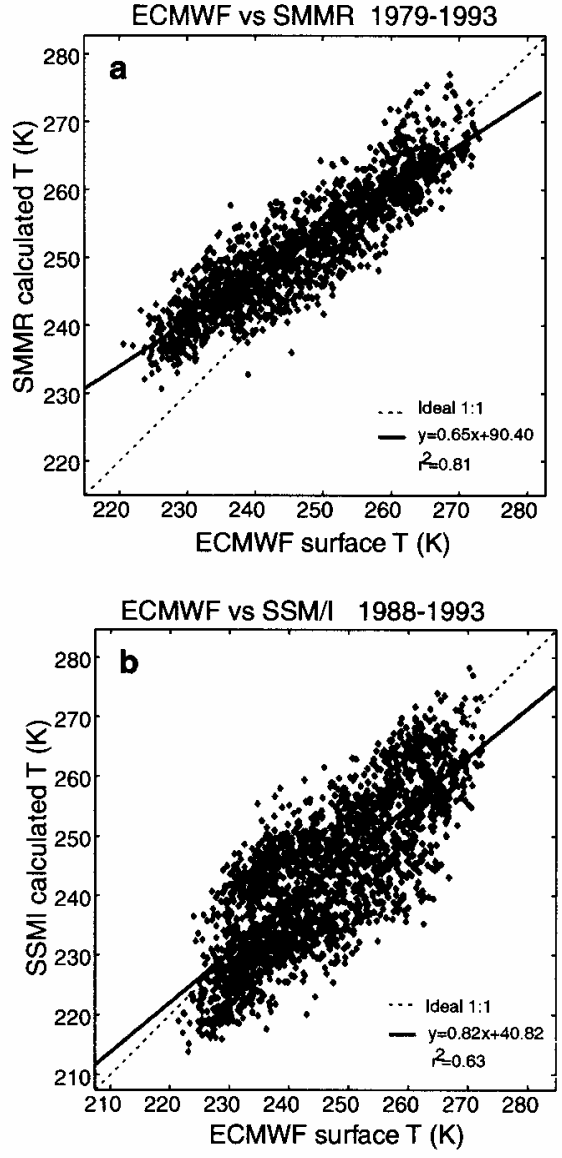

Fig. 3. Scatter plots showing the fit between (a) the meanemissivity corrected SMMR temperatures $T_{\mathrm{C}}$ and ECMWF surface temperatures $T_{\mathrm{S}}$, and (b) mean-emissivity corrected $S S M / I$ temperatures $T_{\mathrm{C}}$ and $E C M W F$ surface temperatures $T_{\mathrm{S}}$.

(e) must be determined either through radiative transfer models or empirically (e.g. Shuman and others, 1995a). We compared daily $37-\mathrm{V} T_{\mathrm{B}}$ values with ERA-15 surface temperature $\left(T_{\mathrm{S}}\right)$ records from the same time period where available. We were able to correlate 9 years of $T_{\mathrm{S}}$ and SMMR 37-V $T_{\mathrm{B}}$ (1979-87) and 5 years of $T_{\mathrm{S}}$ and SSM/I 37-V $T_{\mathrm{B}}$ (1988-93). We then calculated emissivity values for these two overlapping periods by rearranging Equation (1) such that

$$
\begin{aligned}
& e_{1}=T_{\mathrm{B}-\mathrm{SMMR}} T_{\mathrm{S}-\mathrm{ECMWF}^{-1}} \\
& e_{2}=T_{\mathrm{B}-\mathrm{SSM} / \mathrm{I}} T_{\mathrm{S}-\mathrm{ECMWF}^{-1}}
\end{aligned}
$$

(Fig. 2).

We then calculated mean emissivity values for each time period: mean $e_{1}=0.824$ (s.d. $=0.02$ ); mean $e_{2}=0.800$ (s.d. $=$ 0.02). These mean values were next used to generate new calculated temperatures $T_{\mathrm{C}}$ from $T_{\mathrm{B}}$ by rearranging Equation (1) such that

$$
T_{\mathrm{C}}=T_{\mathrm{B}} e^{-1}
$$

The new calculated temperatures are shown in Figure 3 as scatter plots between $T_{\mathrm{C}}$ and $T_{\mathrm{S}}$. This correction technique, using a bulk emissivity, differs slightly from previous work by Shuman and others (1995a) using a similar empirical technique to estimate surface temperature by comparing AWS air temperature and brightness temperatures. In that study (and subsequent work (e.g. Shuman and others, 1995b; Shuman and Stearns, 2001)) they correct for an approximately sinusoidal annual variation in emissivity (a wavelength of 1 year, 
Siple Dome temperature time-series 1979-2000

a

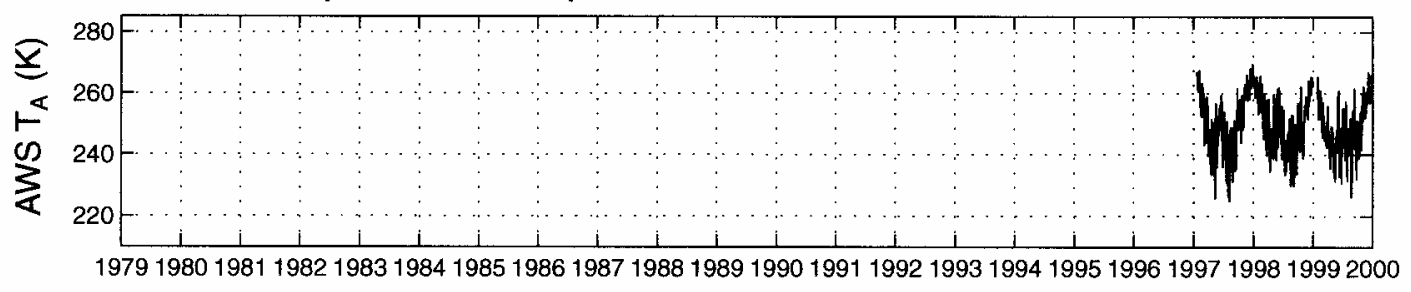

b
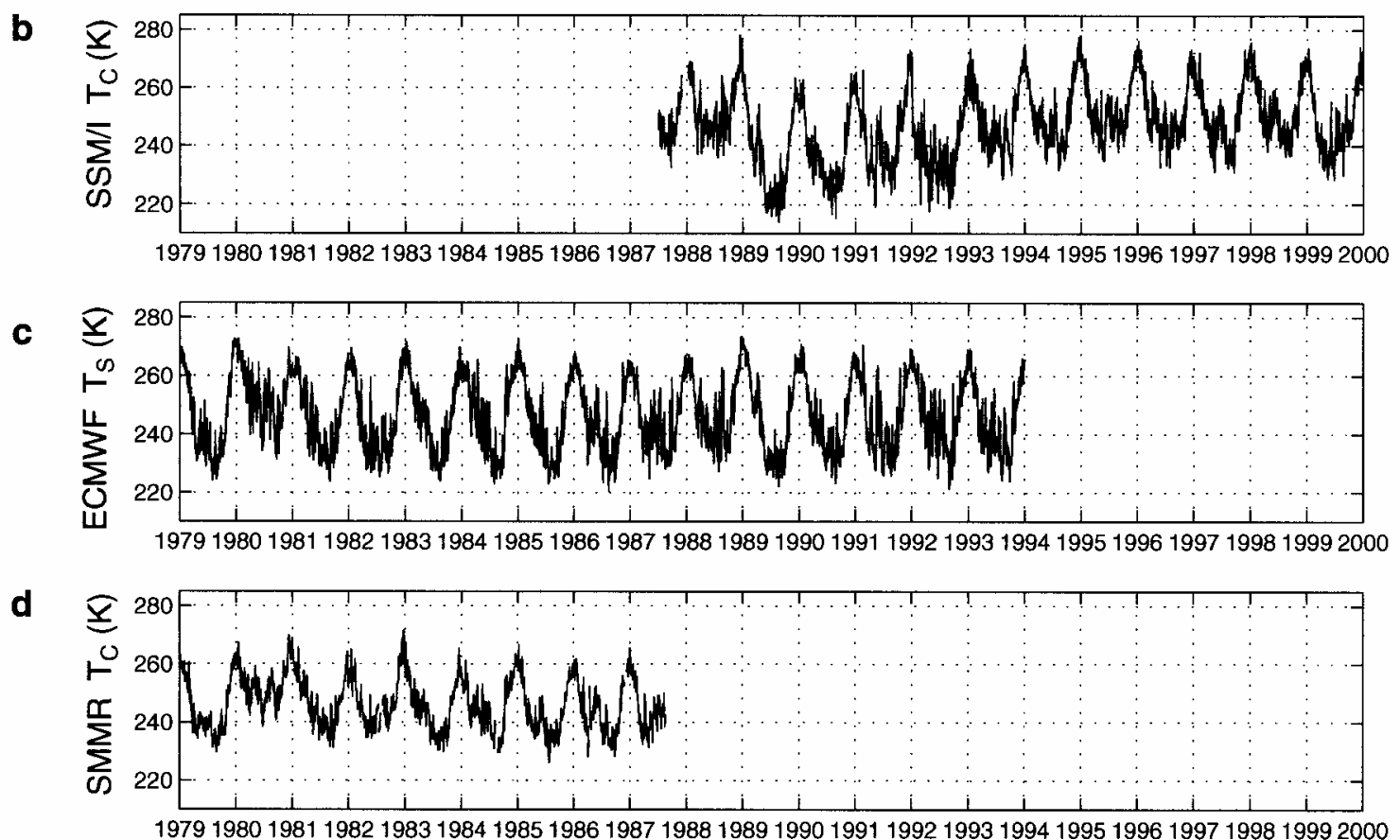

Fig. 4. Time series of daily temperature values used for our analyses: (a) $A W S T_{\mathrm{A}}$, (b) $S S M / I T_{\mathrm{C}}$, (c) $E C M W F T_{\mathrm{S}}$ and (d) $S M M R T_{\mathrm{C}}$ (SMMR only is every other day).

with an amplitude of 0.05). We also find that our calculated emissivities vary annually, especially apparent in $e_{1}$ (Fig. 2a) between 0.8 and 0.85 . But since we are interested in temperature variance over seasonal to annual time-scales rather than absolute daily temperature values (e.g. Shuman and others, 1995a, b, 2001) and because temperature variance is dominated by higher-frequency signals, we can apply a simpler average correction using a mean annual emissivity here.

\section{Anomalous $T_{\mathrm{B}}$ and $e$ values}

One other step we took in calculating corrected SMMR and $\mathrm{SSM} / \mathrm{I} T_{\mathrm{C}}$ values from $T_{\mathrm{B}}$ values was to eliminate a few large, rapid high spikes in $T_{\mathrm{B}}$ during the summer. While Siple Dome is not in a region that undergoes regular seasonal melting, there are occasionally brief surface melting events during the summer (Zwally and Fiegles, 1994; Shuman and Stearns, 2001). During a melt event the occurrence of liquid water at the surface creates a very high microwave emissivity which is reflected in a short-lived spike in $T_{\mathrm{B}}$ (Davis and others, 1987; Zwally and Fiegles, 1994). As this is not a spike in true surface temperature, we removed these $T_{\mathrm{B}}$ values to prevent them from biasing the rest of the record. In many cases, these melt events do not result in a long-term effect on surface emissivity once the liquid water is no longer present. In some instances, though, a near-surface ice layer (a few $\mathrm{mm}$ thick) can be formed in the firn following one of these rare melt events. This results in a rapid drop in emissivity following refreezing. This ice layer causes a depression in emissivity values (manifested as lower than expected $T_{\mathrm{B}}$ values) which persists, albeit with diminishing power, until the ice layer is sufficiently buried below the emitting surface layer and the emissivity gradually returns to pre-melt values. We noticed two separate events which are manifested as drops in snow emissivity over time in our calculations of emissivity (Fig. 2b, drops 1 and 2.) Drop 1 is a more gradual decrease, and may be caused by a period of low to negative accumulation rates. Zero to negative accumulation would result in a coarsening of the grains in the near surface snow (Alley, 1988), thereby reducing the emissivity, which is partially a function of grain-size. We do not have sufficient accumulation data to allow us to further investigate this hypothesis. Drop 2, shown by a large and rapid decrease in snow emissivity, we infer to be caused by the formation of an ice layer in the near-surface following a melt event. SSM/I and other records show unusual warmth and enhanced emissivity associated with this melting event. Furthermore, we identified an ice layer in the firn around Siple Dome (snow-pit stratigraphy and firn-core stratigraphy by S. Das and others during the 1999/2000 and 2000/01 field seasons) which we can date to summer 1991/92. As this ice layer was buried over time, its effect diminished and eventually the average snow emissivity returns to its normal value. Note that the single emissivity value we calculated and used for the whole time series was strongly affected by the formation and presence of this ice layer and so is too low for times when the ice layer was not affecting emissions significantly. The occurrence of both of these events strongly affected the stratig- 

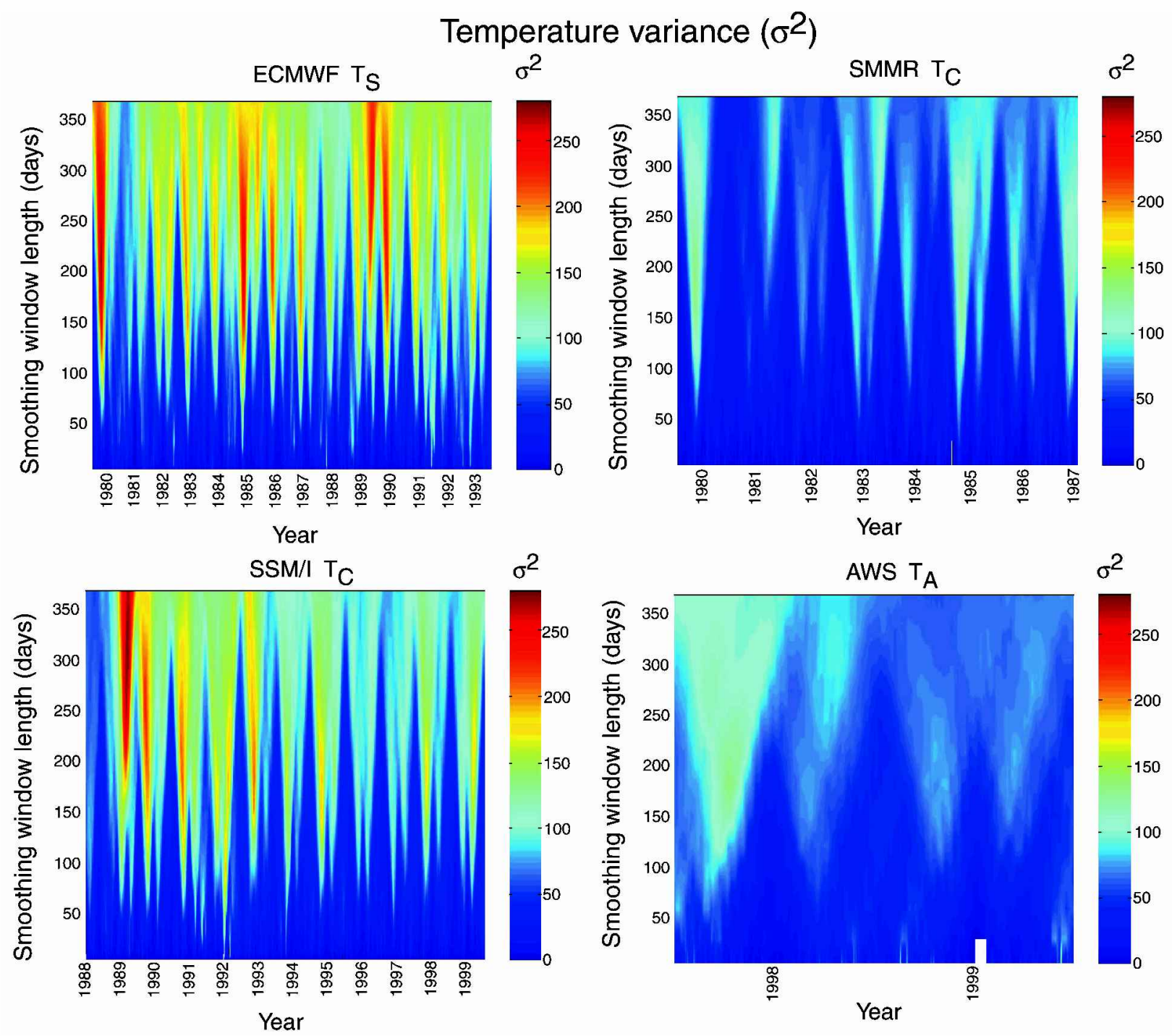

Fig. 5. Diagrams of weekly to annually smoothed temperature variances, constructed from the four different time-series records ( ECMWF, SMMR, SSM/I and AWS). The vertical axis is the length of the smoothing window (7-365 days) used to average the data. Periods of highest temperature variability appear as orange to red spikes.

raphy and emissivity of the surface snow in this region through most of our study period. Furthermore, we cannot be sure that similar events did not occur outside of our calibration period for the SSM/I data (1987-94), which may have affected the emissivity-corrected temperatures for the remainder of the record (1994-99). We therefore urge caution when interpreting the temperature-variance results from the $\mathrm{SSM} / \mathrm{I} T_{\mathrm{C}}$ data.

\section{Time-series analysis}

We can now use these constructed temperature records $T_{\mathrm{A}}, T_{\mathrm{S}}$ and $T_{\mathrm{C}}$ (Fig. 4) to investigate temperature variability in the Siple Dome region. Rather than combine the four temperature records into a single time series, we investigate temperature variability within each of the four records independently (Fig. 5). This minimizes errors resulting from comparing records produced by fundamentally different methods and representing slightly different geophysical parameters. For these four time series comprising daily temperature values $(T)$ we investigate variability by calculating the temperature variance $\left(\sigma^{2}\right)$ across ten different window lengths of interest (number of days $=N$, ranging from 3 days to yearly) (Fig. 5). The temperature variance is calculated as

$$
\sigma^{2}=\frac{\sum\left(T_{i}-\mu\right)^{2}}{N}
$$

where $\left(T_{i}-\mu\right)$ is the deviation of a given daily temperature $\left(T_{i}\right)$ from the mean $(\mu), N$ is the number of observations (days) in the dataset, and the summation $\Sigma$ is across $i=$ $1,2, \ldots, N$ days.

\section{TEMPERATURE VARIABILITY}

Our main result is the observation of anomalously hightemperature-variance "events" $\left(\sigma^{2}>200 \mathrm{~K}^{2}\right.$, shown by the warmer orange- and red-colored spikes in Figure 5) when averaging over the 6 month through 1 year smoothing window. These events occur with a 5 year periodicity. Using the ECMWF $T_{\mathrm{S}}$ record, we find spikes in temperature variance at the end of 1979,1984 and 1990. The spikes appear to occur in the late spring to summer. This spikiness is also apparent in the other temperature records, with the best overlap between the ECMWFand SSM/I results. Although the high levels of variance are not as pronounced in all records, they 


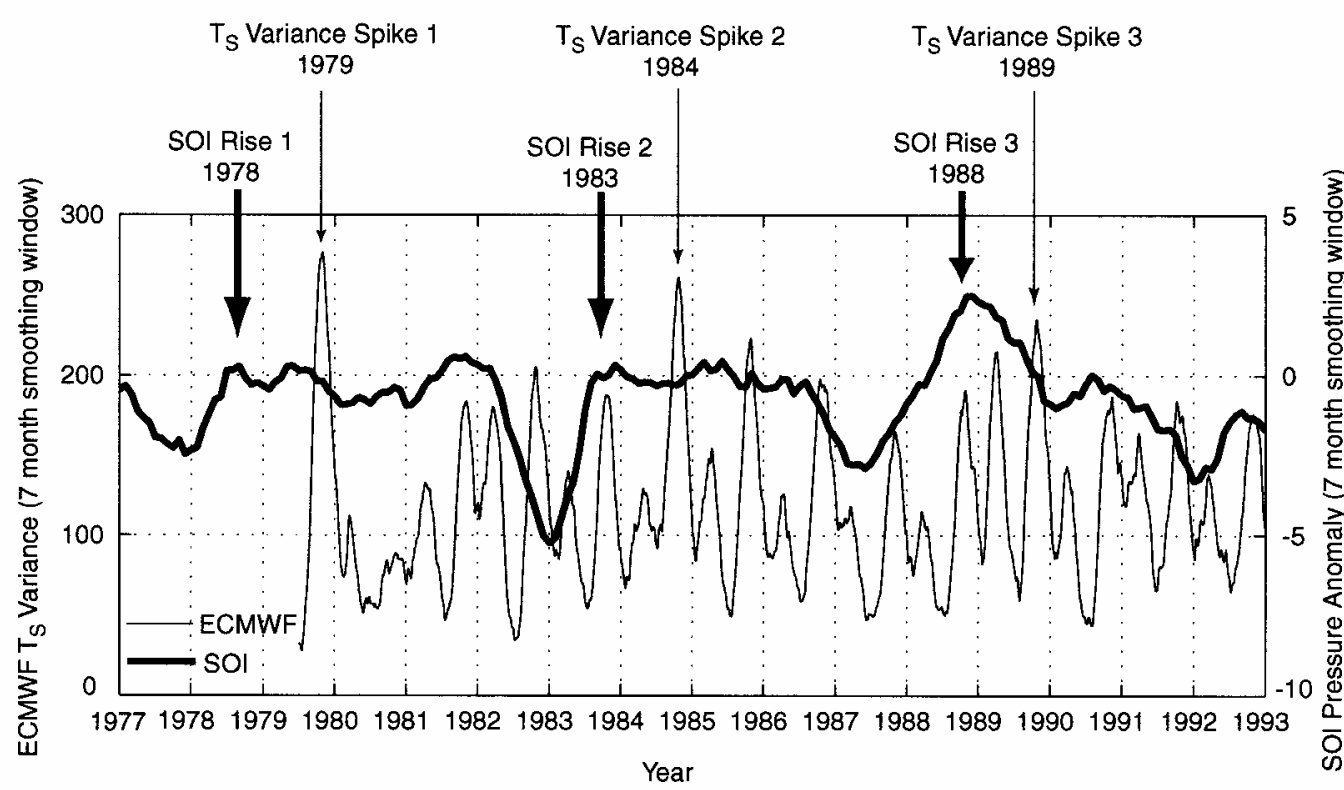

Fig. 6. The ECMWF temperature-variance record (7 month smoothing window) compared to the SOI pressure anomaly (also 7 month smoothing window) showing the repeating pattern of a spike in temperature variability (in 1979, 1984 and 1989) approximately 1 year following a large rise in SOI index from negative to zero or above (in 1978, 1983 and 1988).

still show relative differences from year to year. From the SMMR results we find higher than average temperature variance during 1979 and 1984 corresponding to the highvariance events in the EGMWF record. From the AWS results we find higher than average $\sigma^{2}$ during austral spring 1998 in agreement with $\mathrm{SSM} / \mathrm{I} T_{\mathrm{C}}$. We also see in all of the records alternating periods of high and low seasonal to annual temperature variability (alternating blue and yellow to red patterns in Fig. 5), with lower levels of variability observed more recently. The strong agreement during periods of overlap on patterns of temperature variability in all of the records gives considerable confidence that, despite their differences, all are responding to a common feature of the climate linked to temperature.

If we look in further detail at the three most strongly represented events using our results from the 1979-94 ECMWF $T_{\mathrm{S}}$ record for these summers 1979/80, 1984/85 and 1989/90, we find the winters preceding all three spike events are three of the colder winters observed. As the variation in winter temperature is much greater than the variation in summer temperature, this may be the more important factor in determining the high level of variance. The 5 year periodicity of these events leads us to consider the possibility that they are related to well-documented excursions in the Southern Oscillation Index (SOI), or to El Nino-Southern Oscillation (ENSO) events, which are also known to occur in characteristically 5 year intervals. There are a number of studies documenting possible teleconnection links between the Southern Oscillation, ENSO and Antarctic climate, in both temperature and precipitation (e.g. Mo and White, 1985; Carleton, 1988; Smith and Stearns, 1993; Cullather and others, 1996; Bromwich and others, 2000). Comparing our ECMWF variance record (from the 7 month smoothing window calculations) with the SOI record over the same time period (and also smoothed using a 7 month window) (Fig. 6), we do find three negative SOI anomalies (ENSO years) with similar 5 year spacing during this time. These SOI anomalies do not occur at the same time as the hightemperature-variance spikes, but precede them by lyear.
The negative SOI excursions occur during austral summers 1977/78, 1982/83 and 1987, followed by rising SOI values. The year following a large rise in SOI is characterized by a cold winter relative to the summer that follows, giving rise to the observed variability peaks. We suspect that negative anomalies in the SOI may be driving more variable climate (highly variable temperatures on a sub-annual to annual timescale) through a Southern Hemisphere teleconnection, or perhaps they are both responding to similar forcing mechanisms, with a lag in the surface temperature response. Variations in sea-ice extent can have a strong effect on variations in surface temperatures in coastal zones (e.g. Carleton and others, 1998) and perhaps reach further into West Antarctica. Previous work has also noted 5 year variations in sea-ice extent in the Ross Sea (Jacobs and Giulivi, 1998). These results raise important questions about the controls on seasonal- to decadal-scale climate processes and variability in the Siple Dome/"Ross Embayment" sector.

\section{CONCLUSIONS}

Our results show there is high seasonal to interannual variability in temperature variance from 1979 to 1999 in the Siple Dome region. The annual temperature variance is largely controlled by the highest level of seasonal temperature variance, occurring during the transition from winter into summer as the high variance is strongly reflecting colder than average winters followed by warmer than average summers. Summers (3 month average: roughly December-February) have the most stable temperatures, and show the lowest temperature variance of all seasons throughout the year. Fluctuations in temperature variance occur on a 5 year cycle, and appear to be correlative with variations in the SOI. Over three cycles, a large rise in SOI was followed by a year with a large winter-summer temperature difference and thus resulted in the highest levels of temperature variability. 


\section{ACKNOWLEDGEMENTS}

We thank J.-G. Winther and two anonymous reviewers for constructive comments. The SSM/I and SMMR data used in this study were provided by the NSIDG, University of Colorado. We thank C. Stearns and the Antarctic Automatic Weather Station Project, University of Wisconsin, for the AWS data. The ERA data were provided by the U.S. National Center for Atmospheric Research, Boulder, CO. This research is supported by NASA grant NAG5-7776 and by U.S. National Science Foundation grant OPP-9814485 to The Pennsylvania State University, and by a NASA Earth System Science Fellowship to S. B. Das.

\section{REFERENGES}

Abdalati, W. and K. Steffen. 1995. Passive microwave-derived snow melt regions on the Greenland ice sheet. Geophys. Res. Lett., 22(7), 787-790.

Alley, R. B. 1988. Concerning the deposition and diagenesis of strata in polar firn. F. Glaciol., 34(118), 283-290.

Alley, R. B. 2000. Ice-core evidence of abrupt climate changes. Proc. Natl. Acad. Sci. U.S.A., 97(4), 1331-1334.

Alley, R. B., E. S. Saltzman, K. M. Cuffey and J.J. Fitzpatrick. 1990. Summertime formation of depth hoar in central Greenland. Geophys. Res. Lett., 17(12), 2393-2396.

Alley, R. B., M. K. Spencer and D. E. Voigt. 1997. Visible examination of Siple Dome, West Antarctica, shallow cores. Antart. f. U.S., 32(5), Review 1997, 44-45.

Benson, C. S. 1962. Stratigraphic studies in the snow and firn of the Greenland ice sheet. SIPRE Res. Rep. 70.

Bindschadler, R. A. and 8 others. 1998. What is happening to the West Antarctic ice sheet? Eos, 79 (22), 257, 264-265.

Bromwich, D. H., A. N. Rogers, P. Kållberg, R. I. Cullather, J.W. C. White and K. J. Kreutz. 2000. ECMWF analyses and reanalyses depiction of ENSO signal in Antarctic precipitation. 7. Climate, 13(8), 1406-1420.

Carleton, A. M. 1988. Sea-ice atmosphere signal of the Southern Oscillation in the Weddell Sea, Antarctica. F. Climate, 1(4), 379-388.

Carleton, A. M., G. John and R. G. Welsch. 1998. Interannual variations and regionality of Antarctic sea-ice-temperature associations. Ann. Glaciol., 27, 403-408.

Comiso, J. C. 2000. Variability and trends in Antarctic surface temperatures from in situ and satellite infrared measurements. 7. Climate, 13(10), 1674-1696.

Comiso, J. C., H. J. Zwally and J. L. Saba. 1982. Radiative transfer modeling of microwave emission and dependence on firn properties. Ann. Glaciol., 3, 54-58.

Cullather, R. I., D. H. Bromwich and M. L. VanWoert. 1996. Interannual variations in Antarctic precipitation related to El-Niño-Southern Oscillation. f. Geophys. Res., 101(D14), 19,109-19,118.

Davis, R. E., J. Dozier and A. T. C. Chang. 1987. Snow property measurements correlative to microwave emission at $35 \mathrm{GHz}$. IEEE Trans. Geosci. Remote Sensing, GE-25(6), 751-757.

Foster, J. L., D. K. Hall, A. T. C. Chang and A. Rango. 1984. An overview of passive microwave snow research and results. Rev. Geophys. Space Phys., $22(2), 195-208$.

Genthon, C. and A. Braun. 1995. ECMWF analyses and predictions of the surface climate of Greenland and Antarctica. 7. Climate, 8(10), 2324-2332.

Genthon, C. and G. Krinner. 1998. Convergence and disposal of energy and moisture on the Antarctic polar cap from ECMWF analyses and fore- casts. F. Climate, $11(7), 1703-1716$.

Gibson, R., P. Kållberg, S. Uppala, A. Hernandez, A. Nomura and E. Serrano. 1999. ERA-15. Description version 2. Reading, European Centre for MediumRange Weather Forecasts. (ECMWF Re-Analysis Project Report Series Part 1.)

Hall, D. K. 1987. Influence of depth hoar on microwave emission from snow in northern Alaska. Cold Reg. Sci. Technol., 13(3), 225-231.

Hall, D. K. and J. Martinec. 1985. Remote sensing of ice and snow. London and New York, Chapman and Hall Ltd.

Jacobs, S. S. and C. F. Giulivi. 1998. Interannual ocean and sea ice variability in the Ross Sea. In Jacobs, S. S. and R. F. Weiss, eds. Ocean, ice and atmosphere: interactions at the Antarctic continental margin. Washington, DC, American Geophysical Union, 135-150. (Antarctic Research Series 75.)

Jezek, K. C. and 6others. 1991. Comparison between SMMR and SSM/I passive microwave data collected over the Antarctic ice sheet. Ohio State Univ. Byrd Polar Res. Cen. Tech. Rep. 91-03.

König, M., J.-G. Winther and E. Isaksson. 2001. Measuring snow and glacier ice properties from satellite. Rev. Geophys., 39(1), 1-28.

Maslanik, J. A., J. R. Key and R. G. Barry. 1989. Merging AVHRR and SMMR data for remote sensing of ice and cloud in polar regions. Int. $\mathcal{F}$ Remote Sensing, 10(10), 1691-1696.

Mo, K. C. and G. H.White. 1985. Teleconnections in the Southern Hemisphere. Mon. Weather Rev., 113(1), 22-37.

National Snow and Ice Data Center (NSIDC). 1992. DMSP SSM/I brightnes temperature and sea ice concentration grids for the polar regions on CD-ROM. Users'guide. Boulder, CO, National Snow and Ice Data Center. (Special Report 1.)

Rott, H., K. Sturm and H. Miller. 1993. Active and passive microwave signatures of Antarctic firn by means of field measurements and satellite data. Ann. Glaciol., 17, 337-343.

Shuman, C. A. and C. R. Stearns. 2001. Decadal-length composite inland West Antarctic temperature records. F. Climate, 14(9), 1977-1988.

Shuman, C. A., R. B. Alley and S. Anandakrishnan. 1993. Characterization of a hoar-development episode using $\mathrm{SSM} / \mathrm{I}$ brightness temperatures in the vicinity of the GISP2 site, Greenland. Ann. Glaciol., 17, 183-188.

Shuman, C. A., R. B. Alley, S. Anandakrishnan and C. R. Stearns. 1995a. An empirical technique for estimating near-surface air temperature trends in central Greenland from SSM/I brightness temperatures. Remote Sensing Environ., 51 (2), 245-252.

Shuman, C. A., R. B. Alley, S. Anandakrishnan, J. W. C. White, P. M Grootes and C. R. Stearns. 1995b. Temperature and accumulation at the Greenland Summit: comparison of high-resolution isotope profiles and satellite passive microwave brightness temperature trends. 7. Geophys. Res., 100(D5), 9165-9177.

Smith, S. R. and C. R. Stearns. 1993. Antarctic pressure and temperature anomalies surrounding the minimum in the Southern Oscillation index. 7. Geophys. Res., 98 (D7), 13,071-13,083.

Stearns, C. R. and G. A. Weidner. 1993. Sensible and latent heat flux estimates in Antarctica. In Bromwich, D. H. and C. R. Stearns, eds. Antarctic meteorology and climatology: studies based on automatic weather stations. Washington, DC, American Geophysical Union, 109-138. (Antarctic Research Series 61.)

Stearns, C. R., R. E. Holmes and G. A. Weidner. 1997. Antarctic automatic weather stations: 1996-1997. Antarct. F. U.S., 32(5), Review 1997, 174-178.

Steffen, K., W. Abdalati and J. Stroeve. 1993. Climate sensitivity studies of the Greenland ice sheet using satellite AVHRR, SMMR, SSM/I and in situ data. Meteorol. Atmos. Phys., 51, 239-258.

Van der Veen, C. J. and K. C. Jezek. 1993. Seasonal variations in brightness temperature for central Antarctica. Ann. Glaciol., 17, 300-306.

Zwally, H. J. 1977. Microwave emissivity and accumulation rate of polar firn. f. Glaciol., 18(79), 195-215.

Zwally, H. J. and S. Fiegles. 1994. Extent and duration of Antarctic surface melt. F. Glaciol., 40(136), 463-476. 